\begin{tabular}{c} 
International Journal of Engineering \& Technology, $7(4.38)(2018)$ 800-804 \\
International Journal of Engineering \& Technology \\
WPC \\
Website: www.sciencepubco.com/index.php/IJET \\
Research paper \\
\hline
\end{tabular}

\title{
Research on Effects of Internal Marketing: A Review
}

\author{
Thi Bich Hanh Tran \\ Department of Business Administration, VNU-Vietnam Japan University \\ Luи Huи Phuoc street, My Dinh 1 ward, Nam Tu Liem district, Hanoi, Vietnam \\ *Corresponding authorE-mail: tranthibichhanh@vnu.edu.vn orttb.hanh@vju.ac.vn
}

\begin{abstract}
With the increased competition in the temporary economy, organizations increasingly strive for progressive practices to achieve organizational goals. Internal marketing - treating employees as customers - has recently been suggested as an effective approach to reach positive organizational outcomes. Though research of internal marketing recently increased dramatically, a large number of the studies are case studies and lack strong theoretical backgrounds. A review of internal marketing research is valuable for future research to gain an insight of the research streams of internal marketing and so identifying the compelling areas to pursue. This review attempts to analyze the research of internal marketing and suggest potential directions for future research.
\end{abstract}

Keywords: Internal Marketing, Review, Consequences, Mechanisms

\section{Introduction}

The changing and increasingly competitive economic environment demands organizations to have superior practices in a wide range of aspects for their survival and development, including motivating employees and satisfying customers. Research has accentuated internal marketing - an approach of treating employees as internal customers - as an effective approach to achieving organization's goals. Remarkably, a considerable proportion of empirical research of internal marketing has been recently added, which reflected effectiveness of internal marketing practices and necessitated the execution of internal marketing in organizations. In response to the expansion of internal marketing research with increasingly-added empirical and case studies, a review of internal marketing research is needed to obtain a better insight of effectiveness of internal marketing and identify the potential areas for future research of internal marketing. With these aforementioned goals, this paper aims at reviewing the conceptualization of internal marketing, the consequences of internal marketing, the mechanisms accounting for the effects from internal marketing, the influential factors moderating the effects of internal marketing, and the widely-studied contexts of internal marketing effects.

\section{Internal marketing research}

\subsection{Conceptualization of internal marketing}

Internal marketing was first introduced as "viewing employees as internal customers, viewing jobs as internal products that satisfy the needs and wants of these internal customers while addressing the objectives of the organization" (p.25). ${ }^{1}$ Rafiq \& Ahmed pointed out the difference in conceptualizing internal customers in comparison with the conceptualization in total quality management approach. ${ }^{2}$ The concept of "employees as customers" was captured in both total quality management (TQM) and internal marketing, and it is used rather differently in the two approaches. Specifically, in internal marketing, the focus is on the relationship between the organization and the employee while in TQM, focus is placed more on the relationships between employees themselves. Internal customers in TQM refer to the employees who play both the role of a supplier and that of a customer.

According to Muddie, internal marketing is a human resource management with a marketing twist. ${ }^{3}$ Later, Chelladurai discussed the distinction between these two constructs more clearly. ${ }^{4}$ The study posited that there are overlaps among the processes advocated by the literatures of internal marketing and human resource management. For example, internal products in internal marketing indicate HR strategies and programs. In the same vein, MacStravic pointed out the similarity between internal marketing and HRM to which both of them encompass the efforts of an organization to recruit, train, motivate, and reward its members toward more satisfying marketing behaviors. ${ }^{5}$ The only significant difference between the two is in the advocacy of treating employees as the customers. ${ }^{4}$ Internal marketing focuses on satisfying employees' needs and so motivating them for service mindedness. HRM already has an array of techniques to motivate employees. ${ }^{2}$ However, internal marketing motivates employees by an active marketing approach where marketing-like activities are used internally. ${ }^{6}$

Over time, the research of internal marketing has developed through three stages with a focus on employees' satisfaction, customer orientation, and inter-functional coordination, respectively. ${ }^{7}$ Recently, Gounaris conducted a review of research and later categorized conceptualizations of internal marketing into three types: behavioral - instrumental, mechanic, and holistic approach. ${ }^{8} \mathrm{Be}-$ havioral - instrumental approach views internal marketing as an internally directed strategy focusing on jobs that satisfy the needs of employees, ${ }^{1}$ and this is the most popular approach among researchers. Mechanic approach is relatively popular, to which internal marketing is a means of integrating the different functions that are vital to the customer relations of companies. ${ }^{9}$ Holistic approach combines the features of the previous two approaches such that internal marketing refers to strategies affecting both jobs 
and procedures to enhance company's effectiveness with customers through departmental integration. ${ }^{7}$

Operationally, a large number of the studies have treated internal marketing as a uni-dimensional construct. ${ }^{10-16}$ They view internal marketing as an approach in which organizations treat employees as customers. One similarity aroused from these studies is that they showed a strong interest in examining the mediating mechanisms ${ }^{10} 1113$ or moderating mechanism, ${ }^{12}$ rather than the direct effect of internal marketing on ultimate outcomes. There are two possible reasons for this. First, research of the concept of internal marketing is still in its early stage, so an understanding of the effect of the global construct is still limited. The prior studies have investigated whether the approach of treating employees as internal customers with organization's supportive practices is effective for achieving outcomes. Second, there has been a lack of sound agreement on the sub-components of internal marketing. Other studies examined internal marketing as a multi-dimensional construct. ${ }^{17-23}$ The studies in this ground attempted to examine the direct differential effects of each sub-element of internal marketing on target outcomes, ${ }^{23}$ and they include a different combination of elements of internal marketing.

Concerning measurement, there has been no widely adopted measure of internal marketing. From marketing perspectives, the most common conceptualization comprises four main elements: internal product, internal price, internal place, and internal promotion. ${ }^{24-26}$ Specifically, internal product depicts the values and attitudes of employees for achieving successful marketing strategies and the training courses for developing internal customers' knowledge. It represents the basic needs of internal customers such as the fundamental informational and transactional tools to perform the job, the basic relational and sociological support of coworkers, and educational opportunities beyond the basic provisions of training. Internal place refers to the place and the channels utilized to distribute job products to internal customers. It includes the formal processes and procedures employed in delivering products to internal customers. Internal price refers to the cost to employees for gaining new knowledge. Internal price consists of two dimensions: costly proactive efforts and reactive efforts. Costly proactive efforts refer to the willingness, exertion, and encouragement when anticipating the needs and wants of internal customers. Reactive effort pertains to the internal customer's perception that the internal supplier is responsive and actively pursues resolutions to the internal customer's issues. Lastly, internal promotion indicates the effective communication to employees in cluding the use of face-to-face interactions, recognition, and reward systems. Apart from this conceptualization, Rafiq and Ahmed proposed 7 components of internal marketing which are equivalent to 7Ps of the extended marketing mix. The three additional components include physical evidence, processes, and people. ${ }^{2}$ Nevertheless, the study did not either develop the measure of internal marketing or empirically test the proposal.

A research stream of internal marketing studies is related to examination of sub-elements of internal marketing on outcomes. One special feature of these studies is that there seems to be a limited agreement on the elements of internal marketing, in general. Except for Yao et al..$^{27}$ and Yousefi et al. ${ }^{23}$ that used 4Ps of internal marketing, studies examined different components of internal marketing. However, a review of these studies suggests that the most commonly addressed elements of internal marketing consis of communication ${ }^{17} 20232728$, training, ${ }^{19} 2029$ and empowerment. ${ }^{18}$ 1929

\subsection{Consequences of internal marketing}

Literature has documented rich evidence of the positive effect of internal marketing on employees, organization, external customers, and the development of cross-functional units within the organization. ${ }^{16}$ A majority of the studies centered on employee psychology-related or attitudinal outcomes. Scholarly attention was given the most to organizational commitment ${ }^{10} 13151632-37$, job satisfac- tion $^{8} 303238$ 39 and customer orientation. ${ }^{13}$ 40-44 Some other studies focused on employee work motivation ${ }^{38}$ and job performance ${ }^{19} 27$. Importantly, only a few studies have investigated the influence of internal marketing on employee behaviors, ${ }^{12}{ }^{45}$ and all of them have attended to organizational citizenship behaviors. Apart from these, little empirical evidence is known about the association of internal marketing with other employee behaviors such as employee behaviors directed at customers.

Another group of internal marketing studies focused on examining the effectiveness of internal marketing for organizational outcomes. In this group, researchers have spent most ink on business performance and the results consistently confirmed the effectiveness of internal marketing ${ }^{15} 161846$. Other organizational consequences were also sparingly studied including innovation, ${ }^{20} 47$ knowledge management, ${ }^{23} 4849$ and employee retention. ${ }^{50}{ }^{51} \mathrm{Im}$ portantly, Ling and Greenley indicated that internal marketing is relevant to a wide range of sub-construct of organizational performance including customer satisfaction, relative competitive position, staff attitude, staff retention, and staff compliance. ${ }^{52}$ Vazifehdoost et al. found that internal marketing is linked to organization's market performance (i.e. customer satisfaction and customer loyalty) and financial performance..$^{15}$ Lings and Brook showed that internal marketing is positively related to organization's internal service quality and external service quality. ${ }^{53} \mathrm{Re}-$ markably, there have been only one study addressing brand equity $^{11}$ and another welcome example of organizational culture. ${ }^{49}$ Specially, little has been detected about the connection between internal marketing and brand-related components like brand awareness, brand association, and brand loyalty or discuss the effectiveness of internal marketing from a branding perspective. Evaluating effects of internal marketing from a branding perspective may yield interesting findings because internal marketing is deemed to beget strong motivations for employees, which may be good for building and promoting a positive image of the brand. Similarly, the linkage between internal marketing and organizational culture is still blurred since there are different types of organizational cultures that exist in different degrees in organizations such as organizational learning culture, organizational justice, and organizational knowledge sharing culture.

The third category of internal marketing consequences involves external customer outcomes. The studies in this ground concentrated on customer satisfaction ${ }^{34} 5455$, perceived service quality, ${ }^{32}$ 3845 and customer loyalty. ${ }^{14}$ Among these studies, only Rahmati et al. ${ }^{14}$ and Ghoneim \& Altabie ${ }^{56}$ tested the direct impact of internal marketing on customer outcomes. To be more detailed, Rahmati et al. ${ }^{14}$ examined the direct influence of internal marketing on customer satisfaction. It concluded that the relationship is nonsignificant. Ghoneim \& Altabie ${ }^{56}$ investigated the direct effect on customer loyalty which was sub-divided into cognitive, attitudinal, and behavioral elements. The study found the significant positive effects for all of the relationships, and therefore concluded that internal marketing has a direct positive effect on customer loyalty. Numerically, the number of studies on external customer outcomes is the scantiest among the three groups. As partly shown, the number of studies on customer behavioral outcomes is much smaller compared to the psychological or affective outcomes like customer satisfaction.

Concerning inter-functional coordination, scholars have garnered their interest on only two outcomes so far including interfunctional friction ${ }^{2} 57$ and departmental isolation. ${ }^{58}$ Prior research has also called for more studies to uncover the effectiveness of practices of internal marketing in inter-functional coordination. ${ }^{7}$

\subsection{Mechanisms from internal marketing}

A considerable number of studies have examined the mechanisms for employee or individual outcomes from internal marketing. These studies found that internal marketing is relevant to positive attitude and behavior while the most commonly-studied mecha- 
nisms are also through job satisfaction, organizational commitment, and organizational citizenship behavior. To exemplify, Barzoki and Ghujali found that internal marketing is associated with employee job satisfaction and organizational commitment which in turn result in higher employee performance of organizational citizenship behavior. ${ }^{59}$ Similarly, Ishague and Shahzad empirically confirmed that internal marketing affects employee job satisfaction which later leads to employee job performance and employee engagement in organizational citizenship behavior. ${ }^{60}$ Nevertheless, prior research has shown inconsistent findings about the mediating role of organizational commitment and organizational citizenship behavior for employee market orientation. Concretely, while Awwad and Agti confirmed the significant mediating effect of employee organizational commitment and organizational citizenship behavior between internal marketing and employee market orientation in the banking context, ${ }^{61}$ Gooshki et al. found the insignificant influence on the sample of employees in chain stores. ${ }^{62}$ These pieces of empirical evidence suggest that only a few mechanisms have been studied, and the findings of the mediating effects are still inclusive. Therefore, mechanisms for employee attitudes and behaviors as resulted from internal marketing deserve more research attention.

In terms of possible mediators linking internal marketing to external customer outcomes, most of the studies inserted the influences of employees' psychological states. These studies reasoned that practices of internal marketing positively influence employees' satisfaction and motivation, which then affect external customer satisfaction and loyalty. The two most commonly studied psychological mediators were job satisfaction ${ }^{34} 3555$ and organizational commitment. ${ }^{33}{ }^{34}$ However, results from some studies showed that these are not strong drivers of external customer outcomes ${ }^{34}$. Service quality has also received some attention from researchers. Aburoub et al. ${ }^{63}$ evaluated service quality as the mediator between internal marketing and customer satisfaction and confirmed a significant positive effect. Recently, some researchers have shifted their attention to the influence of employees' behaviors like organizational citizenship behaviors and found encouraging results. ${ }^{63}$ Nevertheless, apart from organizational citizenship behaviors that may be directed at other colleagues in the organization, other behaviors, especially behaviors directed at customers, have not been noticeably studied in relevance to internal marketing.

Table 1: Model of chain effects of internal marketing on external marketing outcomes

\begin{tabular}{|l|l|}
\hline Studies & Models of chain effects of internal marketing \\
\hline $\begin{array}{l}\text { Rafiq \& Ah- } \\
\text { med }\end{array}$ & $\begin{array}{l}\text { Effect of internal marketing on customer orientation, } \\
\text { service quality, and ultimately customer satisfaction. }\end{array}$ \\
\hline Bansal et al. & $\begin{array}{l}\text { Effect of internal marketing on internal customer job } \\
\text { satisfaction, loyalty, trust in management, then extra- } \\
\text { role behaviors directed at external customers which in } \\
\text { turn affect external service quality, customer satisfac- } \\
\text { tion, and loyalty. }\end{array}$ \\
\hline Lings & $\begin{array}{l}\text { Effect of internal marketing (internal market research, } \\
\text { communication, responsiveness) on internal aspects of } \\
\text { performance (employee satisfaction, retention, and } \\
\text { commitment) which later affect external market orienta- } \\
\text { tion and external market performance (customer satis- } \\
\text { faction, retention, and profit). }\end{array}$ \\
\hline Shah & $\begin{array}{l}\text { Effect of internal marketing on employee satisfaction, } \\
\text { productivity, product quality, consumer satisfaction, and } \\
\text { firm performance in the manufacturing sector. }\end{array}$ \\
\hline $\begin{array}{l}\text { Vazidehoost et } \\
\text { al. }\end{array}$ & $\begin{array}{l}\text { Effect of internal marketing on employee organizational } \\
\text { commitment and market orientation which later influ- } \\
\text { ence market performance and financial performance. }\end{array}$ \\
\hline
\end{tabular}

Crucially, there exists a group of studies proposing models of chain effects of internal marketing which in part reflect the mechanisms for organization's financial and market performance. Table 1 shows the chain effects of internal marketing. Nonetheless, a majority of these studies did not provide empirical testing for the proposed models..$^{756465}$ So, empirical validation of these models, particularly cross-cultural validation, is needed.

\subsection{Moderation in internal marketing effects}

With respect to moderating variables in the effect of internal marketing on outcomes, there have been only three attempts on this. Precisely, Chang et al. proposed that employees' online community participation moderates the influence of internal marketing on employee organizational citizenship behaviors. ${ }^{12}$ Huang \& Chen discovered that work status serves as a moderator in the effect of internal marketing on customer orientation and organizational commitment. ${ }^{66}$ Hamilton Ibama and Gladson Nwokah found that organizational commitment is a significant moderator in the internal marketing - market orientation linkage.$^{67}$ Rather than focusing on external customer outcomes, all of these studies centered on employee outcomes. Furthermore, these studied moderators are personal factors. The findings from these studies show that application of internal marketing is influential to foster employee positive attitudes and behaviors, and this phenomenon may be more pronounced depending upon employee individual characteristics. Based on these details, it is clear that the evidence of organizational factors as moderators in internal marketing research has been scarce. This lacuna in research partly needs to be addressed because organizational factors as environments may exert influences on person attitudes and behaviors. There exists a variety of environmental or situational factors in work places, and these factors may be viable simultaneously to employees who operate in such contexts. So, there is a possibility for these environmental factors to interact and co-influence employee attitudes and behaviors. To illustrate, in the context of work place, organizational cultures and organizational climates may be dominant factors to influence employee attitudes and behaviors. There exist some types of organizational cultures or climates in each work place though the dominance of them varies, which shapes the different work contexts. Hence, with specific study contexts, studies may attempt to explore the most relevant organizational cultures or climates such as learning orientation, safety, innovativeness, ethics, and so on. Similarly, companies' environments impact customer attitudes and behaviors, so attending to organizational factors as influential variables in studying the internal marketing - customer responses relationship is vital. Integrating these, the present study identifies that study of moderation, particularly attending to organizational and situational factors, is a fertile ground to pursue.

Table 2: Moderation in the effect of internal marketing on outcomes

\begin{tabular}{|c|c|}
\hline Studies & Moderation effects \\
\hline Chang et al. ${ }^{12}$ & $\begin{array}{c}\text { Internal marketing * employees' online community } \\
\text { participation } \rightarrow \text { Employee organizational citizenship } \\
\text { behavior }\end{array}$ \\
\hline $\begin{array}{c}\text { Huang and } \\
\text { Chen }\end{array}$ & $\begin{array}{c}\text { Internal marketing * work status } \rightarrow \text { customer orienta- } \\
\text { tion and organizational commitment }\end{array}$ \\
\hline $\begin{array}{c}\text { Hamilton Ibama } \\
\text { and Gladson } \\
\text { Nwokah }\end{array}$ & $\begin{array}{c}\text { Internal marketing * organizational commitment } \rightarrow \\
\text { market orientation }\end{array}$ \\
\hline
\end{tabular}

Interestingly, one study treated internal marketing as a moderation. Keelson evaluated internal marketing as a moderator in the relationship between market orientation and business success. ${ }^{68}$ The study confirmed that internal marketing is a significant moderator in the relationship. The result of this study suggests the influential role of internal marketing for influences and outcomes in work places. More research is needed to examine possible moderating role of internal marketing in other relationships and for other outcomes.

\subsection{Studied contexts of effects of internal marketing}

A large number of studies are case studies dedicated to a company or an industry in a specific region. The context can be a bank or a province. Most of them were conducted in European contexts. In terms of industries, internal marketing researchers touched upon a wide range of industries. A vast number of the studies were sam- 
pled in banking firms. ${ }^{102142616970}$ Other industries studied include information technology ${ }^{49}$ education, ${ }^{34} 547172$ nursing, ${ }^{17} 7374$ hotel industry, ${ }^{10}$ social security, ${ }^{13}$ and transportation services. ${ }^{14} 43$ Fewer studies have been found about Asian contexts, particularly new emerging economies where the demands for practices of internal marketing are viable due to increasing competition. Empirical evidence can be found in only context of China ${ }^{75}$, Taiwan, ${ }^{28} 337$ Malaysia $^{1740}$ and Thailand ${ }^{76}$, while the industries focused on most by them are banking and education. This indicates that the relevance of internal marketing practices in many other Asian contexts has not been explored. The current study calls for more empirical validation of effects of internal marketing in Asian contexts, particularly emerging economies that attract a large number of investors such as India, Indonesia, and Vietnam. Additionally, very little research has been conducted to compare the effects of internal marketing in cross-cultural or cross-industry studies. Comparative evidence of internal marketing effects may offer an interesting insight into influence of internal marketing application, which then provide useful managerial implications for different organizations. For evaluating the effectiveness of internal marketing, most of the studies have used the sample of employees while only a few studies have used company managers as the study sample. ${ }^{29}$ Very few studies have been detected about using both managers and employees' responses for assessing the effects of internal marketing. ${ }^{77}$ As such, studies with the data from management and dyadic interactions will be largely valuable for understanding effects pertaining to internal marketing.

\subsection{Recommendations for future research}

Six recommendations are made for future research. First, while internal marketing received attention from both scholars of management and marketing, there exists no formal model and measure of internal marketing. Due to the lack of a formal model and measure of internal marketing, research is called for developing a sound model and measure of internal marketing. To develop a sound model, research needs to employ a compelling conceptualization of internal marketing and a meticulous review of empirical studies in the domain. For a measure of internal marketing, studies may have two attempts including developing a measure for evaluating internal marketing in a specific industry or developing a measure with a focus on a wide range of industries. For the latter, researchers are suggested to test the measure on different industries to warrant measure validity. Second, though a considerable number of studies have examined the effect of internal marketing on employee satisfaction, the results yielded are somewhat inconsistent. Therefore, future research may delve into this phenomenon by testing the robustness of the effect in different contexts. Ideally, conducting cross-cultural studies on this effect may gain interesting insights. According to Awwad \& Agti, ${ }^{61}$ effects of internal marketing on outcomes in different cultures (individual versus collective) may be differential among contexts. Comparing the effect between developed and developing economies, between two different industries, or between two contexts with contrast cultural characteristics can yield interesting results. The third direction for future research involves the consequences of internal marketing. It is recommended for future research to garner a more attention on employee behaviors. For example, researchers might explore the different categories of productive behaviors that employees may perform as a result of organization's execution of internal marketing practices. To be more detailed, researchers may investigate whether internal marketing leads to employee performance of certain behaviors in specific contexts like ethical behavior in selling and cooperative behavior in team projects. Crucially, future research may attend to group or team-leveled consequences as this ground has not been touched while researchers only garnered their interest in individual and organizational outcomes. Studies may, for instance, explore whether the practices of internal marketing is conducive to team performance in projects or not. The reasoning is that internal marketing is deemed to beget motivations for em- ployees in work places which may involve their team projects. Noted, though there exist a vast number of studies explaining the impact of internal marketing for employee positive psychological states and behaviors, research on the relevance of internal marketing for employee well-being - a crucial psychological outcome pertaining to organization's employee-related pursuits is omitted. Hence, this area should be addressed. Similarly, there is still room for future research to attend to other types of behaviors like innovative behavior as it has emerged recently as a critical pursuit while internal marketing researchers neglected its relevance. It is also possible to investigate the chain effect from internal marketing to employee performances then to organizational performances which may show a fuller picture of the effectiveness of internal marketing. The fourth direction future research may pursue is investigation of differential effects of components of internal marketing on outcomes. By focusing on sub-elements of internal marketing, studies may discover the levels of the influences each different sub-factor may exert on outcomes, and so suggesting interesting managerial implications for companies. To illustrate, Alshurideh et al. revealed from empirical data that communication has a strong effect on employee engagement into organizational citizenship behavior while empowerment and training don't have much effect on organizational citizenship behavior. ${ }^{78}$ The study then offered helpful practical implications for companies to foster and enhance employee organizational citizenship behavior and employee productive behaviors in general. Desirably, future studies are recommended to synthesize prominent components of internal marketing, and then evaluating the magnitude of the influence of each component on outcomes. The fifth avenue for research is to study the mechanisms influential in the effect of internal marketing. A fertile ground for studying mechanisms in internal marketing research involves employee behaviors directed at customers and cross-cultural comparisons. Future studies are called to examine more about the impact of behavioral mechanisms. Ideally, studies should apply the Theory of Planned Behavior and accordingly include attitudinal and behavioral components to evaluate the effects of internal marketing. This attempt may allow for an insight in the impact of internal marketing. Finally, future research may test how inter-functional coordination can be achieved for the effective implementation of marketing strategies. This is because a group of studies conceptualize internal marketing as a strategy for enhancing organizational effectiveness through departmental integration while the empirical evidence of this is quite scanty. Assessing effectiveness of internal marketing implementation for inter-functional coordination can reflect whether internal marketing is in the right track as its intended pursuit. Future studies are also recommended to investigate the mechanisms involved in the effect of internal marketing execution on inter-functional or departmental integration.

\section{Conclusion}

Above all, research of internal marketing is still in an early stage with research deficiency in several areas. Though empirical evidence is increasingly added recently, several of the aspects in internal marketing research are overlooked and under-studied. With a review of internal marketing, this study addressed the prominent research streams of internal marketing and identified theoretical gaps in internal marketing research. There seems to lack a formal model and measure of internal marketing. Internal marketing studies have attended to a variety of outcomes resulted from internal marketing, but more research are invited to investigate under-explored and rarely-studied outcomes. The mechanisms from the effect of internal marketing are unclear, and research on influential factors or moderators on the effects of internal marketing is scarce. Future researchers are encouraged to delve more in the conceptualization of internal marketing so as to develop a popularly-recognized model and measure, the consequences resulted from internal marketing, the mechanisms in- 
volved for effects, and the influential factors in the effects of internal marketing.

As a very early study to review the variables related to internal marketing and accordingly point out the research holes, the present study advances the theoretical grounding of internal marketing. It is useful for future research in their research design because they identify deficiency in internal marketing research. The paper is also valuable to managerial field such that it provides management with a comprehensive picture of feasibility of application of internal marketing practices. Through the review, managers may also learn about the most potential elements of internal marketing for achieving certain target outcomes. Furthermore, they know the likely factors to affect effectiveness of practices of internal marketing so that they can channel their most attention on proper areas and have suitable interventions.

\section{References}

[1] L. Berry, J. Ret. Bank. 13 (1981)

[2] M. Rafiq, and P. K. Ahmed, J. Mark. Manag. 9, 3 (1993).

[3] P. Mudie, Euro. J. Mark. 37, 9 (2003).

[4] P. Chelladurai, Editor, Human resource management in sport and recreation, Champaign: Human Kinetics Publishers (2006).

[5] R. S. MacStravic, Healt. Mark. Quart. 3, (1985).

[6] W. R. George, J. Bus. Resea.20 (1990).

[7] M. Rafiq, and P. K. Ahmed, J. Serv. Mark. 14, 6 (2000).

[8] S. P. Gounaris, Internal-market orientation and its measurement. J. Bus. Resea. 59 (2006)

[9] C. Gronroos, Service marketing: Theory and practice. Marketing Science Institute, Cambridge, MA. (1983).

[10] M. Abzari, H. Ghorbani, and F. A. Madani, Inter. J. Mark. Stud. 3, 1 (2011).

[11] S. Azizi, F. Ghytasivand, \& S. Fakharmanesh, Inter. Rev. Manag. \& Mark. 2, 2 (2012).

[12] C. C. Chang, K. H. Tseng, and C. W. Chen, Soc. Behav. \& Pers. 40, 10 (2012)

[13] S. H. Gilanina, M. Taleghani, M. Babaie, Inter. J. Acad. Resea. Bus. $4,10(2013)$

[14] F. Rahmati, A. Falahati, and B. Jamshedynavid, Inter. Resea. J. Appl. \& Bas. Scien. 4, 8 (2013).

[15] H. Vazifehdoost, S. Hooshmand, and E. Dehafarin, Inter. J. Bus. \& Comme. 1, 9 (2012).

[16] K. Zaman, N. Javaid, A. Arshad, and S. Bibi, Inter. J. Bus. \& Soc. Scien. 3, 12 (2012).

[17] C. S. Chang, and H. C. Chang, J. Adv. Nurs. 65, 1 (2009).

[18] F. Makvandi, T. Aghababapoor, and I. N. Mondanipour, Inter. J. Aca. Resea. Bus. \& Soc. Scien. 3, 12 (2013).

[19] P. Mbengo, and M. Chinakidzwa, J. Bus. Admin. \& Edu. 5, 2 (2014).

[20] Mosleh, M. Bahrainizadeh, and A. A. Bouzanjani, J. Bas. Appl. Scien. Resea. 3, 5 (2013).

[21] S. A. Mutharasu, K. Natarajan, and J. A. Filipe, Inter. J. Late. Tren. Finan. \& Econo. Scien. 3, 3 (2013).

[22] Sanchez-Hernandez, and D. Grayson, Intangi. Capit. 8, 2 (2012).

[23] T. Yousefi, H. Teimouri, and J. Jafarpisheh, Inter. J. Acade. Resea. Econo. \& Manag. Scien. 3, 4 (2014).

[24] J. G. Barnes, Iri. Mark. Rev. 4, 2 (1989).

[25] S. B. Keller, D. F. Lynch, A. E. Ellinger, J. Ozment, and R. Calantone, J. Bus. Log. 27, 1 (2006).

[26] N. Piercy, and N. Morgan, Long Range Planning, 24 (1991).

[27] Q. Yao, R. Chen, and G. Cai, Soc. Behav. \& Pers. 41, 4 (2013).

[28] K. M. O. Salem, Inter. J. Learn. \& Devel. 3, 5 (2013).

[29] M. R. Dalvi, and M. Vahidi, Inter. J. Aca. Resea. Bus. \& Soc. Scien. 3, $11(2013)$.

[30] P. K. Ahmed, M. Rafiq, and N. M. Saad, Euro. J. Mark. 37, 9 (2003).

[31] Caruana, and P. Caleya, Inter. J. Bank. Mark. 16, 3 (1998).

[32] Mukherjee, and N. Malhotra, Inter. J. Serv. Indus. Manag. 17, 5 (2006).

[33] Y. Tsai, and S. W. Wu, J. Adv. Nurs. 67, 12 (2011).

[34] S. Altarifi, Inter. J. Bus. \& Manag. 9, 6 (2014)

[35] J. Hung, and T. Lin, J. Inter. Manag. Stud. 3 , 1 (2008).

[36] Farzard, N. Nahavandi, and A. Caruana, Amer. J. Appl. Scien. 5, 11 (2008).
[37] P. Kyriazopoulos, D. Yannacopoulos, A. Spyriadakos, M. Sisoko, and E. Grigoroudis, POMS 18th annu. Conf. Texas: Dallas, (2007).

[38] S. Bell, B. Menguc, and S. Stefani, J. Acad. Mark. Scien. 32, 2 (2004).

[39] Hwang, and D. Chi, Inter. J. Manag. 22, 2 (2005).

[40] Sukati, A. H. Abu Bakar, and B. Rohaizat, Inter. Bus. Manag. 7 (2013).

[41] M. Shahsavani, H. R. Dolatabadi, and B. Ranjbarian, Rep. Opin. 4, 12 (2012)

[42] T. Amangala, and E. Amangala, Europ. J. Bus. \& Manag. 5, 8 (2013).

[43] R. Mohammadi, R. Hashemi, and A. Moradi, Inter. Res. J. Appl. \& Bas. Scien. 3, 11

[44] (2012).

[45] G. O. Yusuf, I. Sukati, and T. A. Chin, Asia. Soci. Scien. 10, 17 (2014).

[46] S. J. Bell, and B. Menguc, J. Retail. 78, 2 (2002).

[47] N. M. Saad, P. K. Ahmed, and M. Rafiq, Asi. Acad. Manag. J. 7, 2 (2002).

[48] S. Choi, Nonprof. Manag. \& Lead. 26, 3 (2015).

[49] G. Mieres, J. A. L. Sanchez, and M. L. S. Vijande, Inter. J. Manag. 29,4 (2012).

[50] Lee, and W. Chen, Inter. J. Manag. 22, 4 (2005).

[51] N. Ahmad, N. Iqbal, M. Sheeraz, Inter. J. Acad. Resea. Bus. \& Soc. Scien. 2, 8 (2012)

[52] J. Ali, M. A. Ahmed, M. Shaharyar, M. Haseeb, and R. Zahoor, Inter, J. Acad. Resea. Bus. \& Soc. Scien. 4, 9 (2014).

[53] N. Lings, and G. E. Greenley, J. Serv. Res. 7, 3 (2005).

[54] N. Lings, and R. Brooks, J. Mark. Manag. 14 (1998).

[55] L. Hung, Soc. Behav. \& Pers. 40, 9 (2012).

[56] H. S. Bansal, M. B. Mendelson, and B. Sharma, J. Qual. Manag. 6 (2001).

[57] Ghoneim, and N. El-Tabie, Proc. 9th Inter. Bus. Soc. Scien. Resea. Conf. (2014).

[58] R. J. Darling, and R. E. Taylor, Euro. J. Mark. 23, 7 (1989).

[59] R. A. Martin, Inter. J. Qual. \& Reliab. Manag. 9, 1 (1992).

[60] S. Barzoki, and T. Ghujali, Inter. J. Acad. Res. Bus. \& Soci. Scien. 3, 3 (2013).

[61] Ishague, and K. Shahzad, Abas. J. Soci. Scien. 9, 1 (2016).

[62] M. Awwad, and D. Agti, Inter. J. Bank Mark. 29, 4 (2011)

[63] S. S. Gooshki, M. Jazvanaghi, M. Kermani, and H. Eskandari, Inter. J. Huma. \&

[64] Cult. Stud. Special issue, (2016).

[65] S. Aburoub, A. M. Hersh, and K. Aladwan, Inter. J. Mark. Stud. 3, 2 (2011).

[66] N. Lings, J. Bus. Resea. 57, 4 (2004).

[67] Shah, Amer. J. Manag. 14, 4 (2014).

[68] M. Huang, and M. Y. Chen, Psychol. Rep. 113, 1 (2013).

[69] L. Hamilton-Ibama, and J. Glason-Nwokah, J. Mark. Devel. 1, 2 (2016).

[70] S. A. Keelson, Rev. Bus. \& Finan. Stud. 5, 1 (2014)

[71] S. I. Al-Hawary, A. K. Al-Qudah, M. P. Abutayeh, M. S. Abutayeh, and D. Y. Al-

[72] Zyadat, Interdiscip. J. Conte. Res. Bus. 4, 9 (2013).

[73] Carauna, and P. Calleys, Inter. J. Ban. Mark. 16, 3 (1998).

[74] S. C. Ting, Edu. Admin. Quart. 47, 2 (2010).

[75] S. M. Yildiz, Univ. J. Edu. Res. 4, 5 (2016).

[76] J. W. Peltier, L. Pointer, and J. A. Schibrowsky, Healt. Mark. Quart. 23, 4 (2008).

[77] J. Cooper, and J. J. Cronin, J. Bus. Res. 48, 3 (2000).

[78] H. Yu, and M. Wang, Inter. Conf. Manag. \& Serv. Scien. (2011).

[79] P. Tansuhaj, J. Wong, and J. McCullough, Inter. J. Bank Mark. 5, 3 (1987).

[80] S. Salajeghe, A. Farahbakhsh, and Z. Sohi, Indi. J. Fundament. \& Appli. Lif. Scien.

[81] 5, 1 (2015).

[82] M. Alshurideh, A. Y. Alhadid, and A. Barween, Inter. J. Mark. Stud. 7, 1 (2015). 